\title{
Low back pain and limitations of daily living in Asia: longitudinal findings in the Thai cohort study
}

\author{
Vasoontara Yiengprugsawan ${ }^{1 *}$ D, Damian Hoy ${ }^{2}$, Rachelle Buchbinder ${ }^{3,4}$, Chris Bain ${ }^{5}$, Sam-ang Seubsman ${ }^{6}$ \\ and Adrian C. Sleigh ${ }^{7}$
}

\begin{abstract}
Background: Low back pain (LBP) is a major cause of disability throughout the world. However, longitudinal evidence to relate low back pain and functional limitations is mostly confined to Western countries. In this study, we investigate the associations between low back pain and functional limitations in a prospective cohort of Thai adults.

Methods: We analysed information from the Thai Cohort Study of adult Open University adults which included 42,785 participants in both 2009 and 2013, with the majority aged 30 to 65 years and residing nationwide. We used multivariate logistic regression to explore the longitudinal associations between LBP in 2009 and 2013 ('never': no LBP in 2009 or 2013; 'reverting': LBP in 2009 but not in 2013; 'incident': no LBP in 2009 but LBP in 2013; and 'chronic': reporting LBP at both time points) and the outcome of functional limitations relating to Activities of Daily Living (ADL) in 2013.

Results: Low back pain was common with 30\% of cohort members reporting low back pain in both 2009 and 2013 ('chronic LBP'). The 'chronic LBP' group was more likely than the 'never' back pain group to report functional limitations in 2013: adjusted odds ratios 1.60 [95\% Confidence Interval: 1.38-1.85] for difficulties getting dressed; 1.98 [1.71-2.30] for walking; 2.02 [1.71-2.39] for climbing stairs; and 3.80 [3.38-4.27] for bending/kneeling. Those with 'incident LBP' or 'reverting LBP' both had increased odds of functional limitations in 2013 but the odds were not generally as high.

Conclusions: Our nationwide data from Thailand suggests that LBP is a frequent public health problem among economically productive age groups with adverse effects on the activities of daily living. This study adds to the limited longitudinal evidence on the substantial impact of low back pain in Southeast Asia.
\end{abstract}

Keywords: Low back pain, Functional limitations, Activities of daily living, Cohort study, Thailand

\section{Background}

Across the adult lifespan, low back pain (LBP) is very common $[1,2]$. In Western settings, evidence suggests LBP affects 40 to $60 \%$ of working adults and adversely impacts quality of life, frequently on a daily basis $[3,4]$. Low back pain can lead to severe and long term impairment.

\footnotetext{
* Correspondence: vasoontara.yieng@anu.edu.au; vasoontara.yieng@gmail.com

${ }^{1}$ Centre for Research on Ageing, Health and Wellbeing and Department of Global Health, Research School of Population Health, The Australian National University, Canberra, Australia

Full list of author information is available at the end of the article
}

The Global Burden of Disease Study listed LBP as a major cause of disability among musculoskeletal conditions and ranked LBP in the top five conditions contributing to loss of disability-adjusted life years [5, 6].

In the past decade, with its impact on productivity and activities of daily living, LBP has gained increasing attention in developing countries worldwide [2, 7]. These include, for example, a study among rural Tibetans noted LBP prevalence of 34\% [8] and another study across occupation groups in Shanghai reported LBP prevalence ranging from $40 \%$ among teachers to $74 \%$ among garment workers [9]. LBP has a tendency to become chronic and a 
systematic review of prospective cohort studies for LBP in office workers noted previous low back pain was a key factor for subsequent pain [10]. However, longitudinal evidence relating to causes and consequences of LBP remains limited, especially in low and middle-income countries.

In this paper, we focus on LBP in a large nationwide prospective cohort of Thai adults. We investigate longitudinal associations of LBP and functional limitations of daily living. We provide an estimate of the magnitude of LBP in working adults and its consequences 4 years later, thus adding to the evidence base of low back pain globally, and in middle-income countries such as Thailand.

\section{Methods}

This research is part of an overarching study of the healthrisk transition underway in Thailand as maternal and child mortality and infectious diseases recede and chronic noncommunicable diseases emerge [11]. To analyse the transition, we have developed a Thai Cohort Study enrolling 87,151 Sukhothai Thammathirat Open University distance learning adult students with a baseline 20-page comprehensive health and socio-physical-environment questionnaire in 2005. These cohort members share key sociodemographic characteristics with the general Thai population such as geographical distribution, modest median income, sex ratio, religion and ethnicity [12]. They were successfully followed up 4 and 8 years later (approximately $70 \%$ response rate in each wave; $n=60,569$ in 2009 and $n=42,785$ in 2013). The cohort from 2009 to 2013 is the population reported here.

Low back pain exposure and functional limitation outcomes In both 2009 and 2013, cohort members were asked standardised questions about LBP and if it was bad enough to limit usual activities or change daily routines for more than one day [13]. The English version of the questions and the standard diagram in 2013 are as shown in Additional file 1. It should be noted that the Thai interpretation of the standard LBP diagram initially did not cover the whole lower buttock area, but this was resolved in 2013. The age stratified crude prevalence of LBP in 2013 was slightly higher compared with 2009; among other things, this could be explained by the larger anatomical area included in the 2013 diagram.

We separately classified LBP and 'severe' LBP across the 4 years as longitudinal categories: 'never' ('no' in 2009 and in 2013), 'reverting' ('yes' in 2009 and 'no' in 2013); 'incident' ('no' in 2009 and 'yes' in 2013); and 'chronic' ('yes' in 2009 and in 2013).

In 2013, cohort members were asked about their functional limitations related to Activities of Daily Living (ADL) in the past 4 weeks [14]: 1) climbing stairs; 2) walking 100 metres; 3) bending, kneeling or stooping; and 4) dressing. Possible responses were: 'not at all'; 'a little'; 'a lot'. The ADL questions were not connected to low back pain questions.

\section{Potential confounders}

We collected a range of sociodemographic, behavioural and health information from cohort members at 2009 and 2013 follow-up. We also noted various other characteristics as reported in 2009 that could influence activities of daily living, including age, sex, urban-rural residence, and household monthly income (Thai Baht; 1\$US 30Baht). Occupation and work hours, available in the 2013 follow-up data, were used in the analyses. The average 2009-2013 values of four other covariates were used as follows: hours of standing and hours of sitting per day; physical activity (combined number of moderate or vigorous sessions per week); and body mass index (based on self-reported weight and height measurements) using recommended Asian cut-offs for overweight and obesity [15-17].

\section{Statistical analyses}

We analyse associations between 4-year low back pain and each of the four activity of daily living outcomes as measured in 2013 (ie climbing stairs, walking 100 metres, bending/kneeling, and getting dressed). Each functional limitation model included the longitudinal 2009-2013 LBP category (never-reverting-incident-chronic) as the independent variable of interest. Multivariate logistic regression was used for analyses reporting Odds Ratios and 95\% Confidence Intervals, adjusting for the potential confounders. Individuals with missing data for any given analysis were excluded ( $<5 \%$ for each variable), thus totals could vary slightly due to available information.

\section{Results}

Cohort characteristics are summarised in Table 1: $45 \%$ were males; close to $80 \%$ were aged between 30 and 50 years; $55 \%$ resided in urban areas; and about $70 \%$ were managers, professionals or office workers. Table 1 also shows the prevalence of LBP and severe LBP by longitudinal categories (never, reverting, incident, chronic). For LBP, 37\% were classified as 'never'; $20 \%$ as 'reverting'; $13 \%$ as 'incident'; and $30 \%$ as 'chronic'. For severe LBP, the corresponding prevalences were $95.3 \%, 1.7 \%$. $2.3 \%$ and $0.7 \%$. Notably, cohort members who had a high prevalence of 'chronic LBP' in both 2009 and 2013 were physical (skilled or elementary) workers (35\%), with lower household income (36\%), $9 \mathrm{~h}+$ standing daily (40\%), and a body mass index of $30+(34 \%)$.

Table 2 describes functional limitations among cohort members in 2013: approximately $6 \%$ of the cohort reported difficulty bending, 3.1\% walking 100 metres, 2.2\% climbing stairs, and $2.9 \%$ dressing oneself. There was a 
Table 1 Cohort attributes by prevalence of low back pain $(N=42785)$, Thai Cohort Study

\begin{tabular}{|c|c|c|c|c|}
\hline \multirow{2}{*}{$\begin{array}{l}\text { Low back pain status and } \\
\text { cohort attributes in } 2013(\%)\end{array}$} & \multicolumn{4}{|c|}{ Longitudinal 2009-2013 low back pain dynamics ${ }^{a}$} \\
\hline & $\begin{array}{l}\text { Never } \\
\text { 'No' } 2009 \text { \& } \\
\text { 'No' } 2013 \\
\end{array}$ & $\begin{array}{l}\text { Reverting } \\
\text { 'Yes' } 2009 \text { \& } \\
\text { 'No' } 2013 \\
\end{array}$ & $\begin{array}{l}\text { Incident } \\
\text { 'No' } 2009 \text { \& } \\
\text { 'Yes' } 2013 \\
\end{array}$ & $\begin{array}{l}\text { Chronic } \\
\text { 'Yes' } 2009 \text { \& } \\
\text { 'Yes' } 2013 \\
\end{array}$ \\
\hline Low back pain & 36.8 [14768] & $20.0[8055]$ & $13.0[5235]$ & $30.0[12042]$ \\
\hline Severe low back pain restricting activities ${ }^{b}$ & $95.3[38260]$ & $1.7[701]$ & $2.3[922]$ & $0.7[271]$ \\
\hline \multicolumn{5}{|l|}{ Sex } \\
\hline Male (45.1\%) & 38.1 & 19.1 & 13.4 & 29.5 \\
\hline Female (54.8\%) & 35.8 & 20.9 & 12.8 & 30.5 \\
\hline \multicolumn{5}{|l|}{ Age group, years } \\
\hline$<35(28.4 \%)$ & 36.3 & 20.6 & 13.3 & 29.9 \\
\hline $35-44(45.5 \%)$ & 35.8 & 20.5 & 13.2 & 30.4 \\
\hline $45+(30.2 \%)$ & 38.8 & 19.0 & 12.6 & 29.7 \\
\hline \multicolumn{5}{|l|}{ Residence } \\
\hline Urban (55.3\%) & 35.6 & 19.6 & 13.3 & 31.4 \\
\hline Rural (44.7\%) & 37.7 & 20.5 & 12.8 & 28.9 \\
\hline \multicolumn{5}{|l|}{ Occupation } \\
\hline Professional and managers (40.3\%) & 38.5 & 20.0 & 13.3 & 27.9 \\
\hline Office assistant (30.5\%) & 36.4 & 20.9 & 12.6 & 30.2 \\
\hline Skilled worker/elementary (18.7\%) & 32.5 & 19.1 & 13.6 & 34.9 \\
\hline Others/not working (10.4\%) & 38.4 & 19.8 & 13.5 & 29.4 \\
\hline \multicolumn{5}{|l|}{ Work hours per week } \\
\hline$<25(7.2 \%)$ & 34.8 & 19.8 & 13.5 & 31.8 \\
\hline $25-40(34.2 \%)$ & 38.6 & 20.4 & 13.1 & 27.8 \\
\hline $40+(43.9 \%)$ & 35.6 & 19.8 & 13.1 & 31.4 \\
\hline Not working (14.5\%) & 36.9 & 20.2 & 12.4 & 30.4 \\
\hline \multicolumn{5}{|l|}{ Household monthly income } \\
\hline$\leq 10,000$ Baht (12.4\%) & 32.8 & 18.9 & 12.6 & 35.7 \\
\hline$>10,000$ to 30,000 Baht (41.6\%) & 34.9 & 20.5 & 13.1 & 31.6 \\
\hline > 30,000 Baht (45.8\%) & 39.6 & 20.0 & 13.2 & 27.2 \\
\hline \multicolumn{5}{|l|}{ Hours sitting per day } \\
\hline $0-4(25.4 \%)$ & 36.6 & 20.1 & 12.6 & 30.7 \\
\hline $5-8(46.6 \%)$ & 37.4 & 20.2 & 13.1 & 29.3 \\
\hline$>8(27.8 \%)$ & 36.1 & 19.9 & 13.4 & 30.6 \\
\hline \multicolumn{5}{|l|}{ Hours standing per day } \\
\hline 0-4 (70.9\%) & 37.4 & 20.0 & 13.3 & 29.3 \\
\hline $5-8(22.9 \%)$ & 35.7 & 20.7 & 12.2 & 31.4 \\
\hline$>8(6.1 \%)$ & 33.7 & 19.2 & 13.2 & 33.9 \\
\hline \multicolumn{5}{|l|}{ Physical activity sessions per week ${ }^{c}$} \\
\hline$<3(50.2 \%)$ & 35.7 & 19.9 & 13.5 & 30.9 \\
\hline $3-6(37.5 \%)$ & 38.2 & 20.5 & 12.9 & 28.5 \\
\hline $7+(12.2 \%)$ & 37.5 & 19.7 & 11.8 & 31.0 \\
\hline \multicolumn{5}{|l|}{ Body mass index (Asian cut offs) } \\
\hline Underweight: $\mathrm{BMI}<18.5$ (5.7\%) & 37.6 & 21.6 & 12.1 & 28.7 \\
\hline
\end{tabular}


Table 1 Cohort attributes by prevalence of low back pain $(N=42785)$, Thai Cohort Study (Continued)

\begin{tabular}{lllll}
\hline Normal: BMI 18.5 to $<23(43.7 \%)$ & 38.0 & 19.8 & 12.9 & 29.4 \\
Overweight: BMI 23 to $<25(21.7 \%)$ & 36.2 & 20.4 & 13.6 & 13.7 \\
Obese I: BMI 25 to $<30(23.4 \%)$ & 34.9 & 19.5 & 13.0 & 31.9 \\
Obese II: BMI 30+ (5.3\%) & 32.4 & 20.7 & 34.0 \\
\hline
\end{tabular}

absed on status in 2009 and 2013 as follows: never, reverting, incident, and chronic

b'Severe' defined as low back pain bad enough to limit usual activities for more than one day

${ }^{\mathrm{c} C o m b i n e d ~ n u m b e r ~ o f ~ m o d e r a t e ~ o r ~ v i g o r o u s ~ s e s s i o n ~(~} \geq 20 \mathrm{~min}$ per session)

gradient of increasing functional limitation across all activities as LBP status became increasingly proximate in time ('never' to 'reverting' to 'incident' to 'chronic').

Table 3 shows the associations between 2013 functional limitations and 2009-2013 longitudinal categories of LBP (never, reverting, incident and chronic), adjusting for the potential confounders listed in Table 1. 'Chronic' LBP was associated with the highest odds of functional limitations: Adjusted Odds Ratios and 95\% CI were 1.60 [1.38-1.85] for difficulties getting dressed; 1.98 [1.712.30] for walking; 2.02 [1.71-2.39] for climbing stairs; and 3.80 [3.38-4.27] for bending or kneeling. 'Incident' LBP had similar OR patterns but the odds were not as high - corresponding AORs for each ADL limitations were 1.49 [1.28-1.80], 1.76 [1.46-2.12], 1.53 [1.22-1.91], and 2.65 [2.29-3.06], respectively. Notable among the behavioural variables with significant associations with all ADL limitations were hours of standing (except for difficulty walking) and overweight to obese body mass index.

Those with 'severe' low back pain showed similar patterns but with higher odds of functional limitations; this is not explored further due to the relative rarity of severe LBP resulting in a small sample for statistical inference.

\section{Discussion and conclusions}

Low back pain was common in our cohort and approximately one third of participants reported LBP in both 2009 and 2013. We found an association between low back pain status from 2009 to 2013 and functional limitations for ADL in 2013, with increased limitations among those with severe low back pain. As well, ADL limitation was high among those with 'chronic' LBP (in both 2009 and 2013) and that limitation was greater than for those with 'incident' LBP, which in turn was

Table 2 Low back pain dynamics in the Thai Cohort Study (2009-2013) by functional limitations

\begin{tabular}{|c|c|c|c|c|c|}
\hline \multirow{2}{*}{$\begin{array}{l}\text { Functional } \\
\text { limitations }\end{array}$} & \multirow[t]{2}{*}{$2013 \%$} & \multicolumn{4}{|c|}{ Longitudinal 2009-2013 low back pain dynamics by functional limitations, \% ( $n$ ) } \\
\hline & & $\begin{array}{l}\text { Never } \\
\text { 'No' } 2009 \text { \& } \\
\text { 'No' } 2013 \\
\end{array}$ & $\begin{array}{l}\text { Reverting } \\
\text { 'Yes' } 2009 \text { \& } \\
\text { 'No' } 2013 \\
\end{array}$ & $\begin{array}{l}\text { Incident } \\
\text { 'No' } 2009 \text { \& } \\
\text { Yes } 2013\end{array}$ & $\begin{array}{l}\text { Chronic } \\
\text { 'Yes' } 2009 \text { \& } \\
\text { 'Yes' } 2013\end{array}$ \\
\hline \multicolumn{6}{|c|}{ Climbing stairs } \\
\hline Never & 84.5 & $89.9(13225)$ & $87.1(6985)$ & $81.9(4246)$ & $77.8(9256)$ \\
\hline A little & 13.2 & $8.4(1240)$ & $11.0(886)$ & $15.6(813)$ & $18.9(2257)$ \\
\hline A lot & 2.2 & $1.6(236)$ & $1.7(140)$ & $2.4(126)$ & $3.2(383)$ \\
\hline \multicolumn{6}{|c|}{ Walking 100 metres } \\
\hline Never & 81.3 & $87.6(12855)$ & $84.6(6764)$ & $78.1(4050)$ & $73.0(8679)$ \\
\hline A little & 15.7 & $10.3(1515)$ & $13.0(1041)$ & $18.2(946)$ & $22.7(2702)$ \\
\hline A lot & 3.1 & $2.1(304)$ & $2.3(187)$ & $3.5(186)$ & $4.1(497)$ \\
\hline \multicolumn{6}{|c|}{ Bending/stooping } \\
\hline Never & 56.7 & 71.5 (10519) & $64.3(5153)$ & $45.9(2397)$ & $37.8(4524)$ \\
\hline A little & 37.4 & $27.2(4708)$ & $31.6(2537)$ & $46.7(2438)$ & $51.7(6192)$ \\
\hline A lot & 5.9 & $2.8(410)$ & $3.9(318)$ & $7.2(378)$ & 10.3 (1239) \\
\hline \multicolumn{6}{|c|}{ Dressing self } \\
\hline Never & 82.8 & 88.4 (12978) & 85.5 (6829) & $79.1(4105)$ & 75.7 (8977) \\
\hline A little & 14.2 & $9.3(1374)$ & $11.7(941)$ & $17.3(901)$ & $20.4(2428)$ \\
\hline A lot & 2.9 & $2.2(327)$ & $2.7(216)$ & $3.4(178)$ & $3.8(451)$ \\
\hline
\end{tabular}


Table 3 Association between 2009 and 2013 longitudinal low back pain dynamics and 2013 functional limitations adjusting for potential covariates, Thai cohort study

\begin{tabular}{|c|c|c|c|c|}
\hline \multirow{2}{*}{$\begin{array}{l}\text { Exposure variables } \\
\text { Low back pain category (2009 to 2013) }\end{array}$} & \multicolumn{4}{|c|}{ Outcomes - adjusted odds ratios [95\% Confidence Intervals] $]^{a}$} \\
\hline & Climbing stairs & Walking 100 m & Bending/kneeling & Getting dressed \\
\hline Never - 'No' in 2009 \& 'No' in 2013 & Reference & Reference & Reference & Reference \\
\hline Reverting - 'Yes' in 2009 \& 'No' in 2013 & $1.10[0.89-1.36]$ & $1.14[0.95-1.38]$ & $1.41[1.21-1.64]$ & $1.18[0.99-1.41]$ \\
\hline Incident - 'No in 2009 \& 'Yes' in 2013 & $\mathbf{1 . 5 3}[1.22-1.91]$ & $1.76[1.46-2.12]$ & $2.65[2.29-3.06]$ & $1.49[1.28-1.80]$ \\
\hline Chronic - 'Yes' in 2009 \& 'Yes' in 2013 & $2.02[1.71-2.39]$ & $1.98[1.71-2.30]$ & $3.80[3.38-4.27]$ & $\mathbf{1 . 6 0}[1.38-1.85]$ \\
\hline \multicolumn{5}{|l|}{ Covariates $\left(2009\right.$, except $^{\mathrm{b}}$ and $\left.{ }^{\mathrm{c}}\right)$} \\
\hline \multicolumn{5}{|l|}{ Sex } \\
\hline Females (male - ref) & $\mathbf{1 . 1 9}[1.02-1.37]$ & $1.03[0.90-1.16]$ & $1.36[1.24-1.50]$ & $1.39[1.23-1.59]$ \\
\hline \multicolumn{5}{|l|}{ Age groups (years) } \\
\hline$<35$ & Reference & & & \\
\hline $35-44$ & $0.91[0.76-1.07]$ & $0.93[0.80-1.07]$ & $0.98[0.88-1.10$ & $\mathbf{0 . 7 1}[0.61-0.81]$ \\
\hline $45+$ & $0.95[0.78-1.15]$ & $0.96[0.81-1.13]$ & $1.35[1.20-1.52]$ & $0.56[0.47-0.66]$ \\
\hline \multicolumn{5}{|l|}{ Residence } \\
\hline Urban (rural - ref) & $0.97[0.84-1.12]$ & $0.93[0.82-1.05]$ & $0.95[0.87-1.04]$ & $1.02[0.90-1.15]$ \\
\hline \multicolumn{5}{|l|}{ Occupation $^{\text {b }}$} \\
\hline Professionals and managers & Reference & & & \\
\hline Office assistant & $1.08[0.91-1.27]$ & $1.11[0.96-1.29]$ & $1.00[0.90-1.12]$ & $0.97[0.84-1.13]$ \\
\hline Skilled or elementary workers & $0.79[0.64-0.98]$ & $1.05[0.88-1.24]$ & $1.13[0.99-1.28]$ & $0.86[0.72-1.03]$ \\
\hline Others/ not working & $1.02[0.73-1.41]$ & $0.94[0.71-1.25]$ & $1.22[0.98-1.51]$ & $\mathbf{0 . 6 8}[0.51-0.91]$ \\
\hline \multicolumn{5}{|l|}{ Work hours per week ${ }^{b}$} \\
\hline$<25$ & $\mathbf{1 . 5 4}[1.20-1.98]$ & $1.41[1.14-1.76]$ & $1.27[1.08-1.50]$ & $\mathbf{1 . 5 5}[1.25-1.92]$ \\
\hline $25-40$ & Reference & & & \\
\hline $40+$ & $1.04[0.88-1.23]$ & $0.96[0.83-1.11]$ & $1.01[0.91-1.12]$ & $0.94[0.81-1.08]$ \\
\hline Not working & $1.45[1.08-1.95]$ & $1.39[1.08-1.79]$ & $1.14[0.94-1.39]$ & $1.65[1.28-2.11]$ \\
\hline \multicolumn{5}{|l|}{ Household monthly income (Baht) } \\
\hline$\leq 10,000$ & $1.04[0.86-1.24]$ & $1.24[1.07-1.44]$ & $1.10[0.98-1.24]$ & $1.03[0.88-1.21]$ \\
\hline$>10,000-30,000$ & Reference & & & \\
\hline$>30,000$ & $1.01[0.86-1.19]$ & $0.88[0.76-1.02]$ & $0.90[0.82-1.00]$ & $0.97[0.84-1.11]$ \\
\hline \multicolumn{5}{|l|}{ Hours sitting per day ${ }^{c}$} \\
\hline $0-4$ & $1.39[1.17-1.65]$ & $\mathbf{1 . 5 2}[1.32-1.76]$ & $1.11[0.98-1.24]$ & $\mathbf{1 . 2 1}[1.03-1.41]$ \\
\hline $5-8$ & Reference & & & \\
\hline $9+$ & $\mathbf{0 . 7 7}[0.65-0.91]$ & $\mathbf{0 . 8 3}[0.72-0.96]$ & $0.90[0.82-1.00]$ & $0.82[0.71-0.94]$ \\
\hline \multicolumn{5}{|l|}{ Hours standing per day ${ }^{c}$} \\
\hline $0-4$ & $1.15[0.96-1.34]$ & $0.95[0.83-1.09]$ & $1.05[0.95-1.17]$ & $1.17[1.01-1.36]$ \\
\hline $5-8$ & Reference & & & \\
\hline $9+$ & $1.40[1.07-1.84]$ & $0.91[0.71-1.16]$ & $1.33[1.12-1.58]$ & $1.49[1.18-1.89]$ \\
\hline \multicolumn{5}{|l|}{ Physical activity (moderate or rigorous) ${ }^{c}$} \\
\hline$<3$ sessions/week & Reference & & & \\
\hline 3-6 sessions/week & $0.89[0.76-1.04]$ & $0.91[0.80-1.04]$ & $\mathbf{0 . 7 9}[0.72-0.87]$ & $\mathbf{0 . 8 3}[0.72-0.95]$ \\
\hline $7+$ sessions/week & $1.06[0.86-1.32]$ & $1.32[1.11-1.57]$ & $0.93[0.81-1.07]$ & $1.05[0.87-1.27]$ \\
\hline \multicolumn{5}{|l|}{ Body mass index (Asian cut offs) ${ }^{c}$} \\
\hline Underweight $(<18.5)$ & $1.06[0.79-1.43]$ & $1.09[0.84-1.41]$ & $0.89[0.72-1.10]$ & $\mathbf{0 . 7 1}[0.51-0.97]$ \\
\hline
\end{tabular}


Table 3 Association between 2009 and 2013 longitudinal low back pain dynamics and 2013 functional limitations adjusting for potential covariates, Thai cohort study (Continued)

\begin{tabular}{lllll}
\hline Normal $(18.5$ to $<23)$ & Reference & & & \\
Overweight $(23$ to $<25)$ & $\mathbf{1 . 2 5}[1.04-1.51]$ & $\mathbf{1 . 2 1}[1.03-1.42]$ & $\mathbf{1 . 3 3}[1.18-1.49]$ & $\mathbf{1 . 6 0}[1.35-1.89]$ \\
Obese I $(25$ to $<30)$ & $\mathbf{1 . 4 2}[1.19-1.70]$ & $\mathbf{1 . 3 3}[1.13-1.55]$ & $\mathbf{1 . 7 3}[1.54-1.93]$ & $\mathbf{2 . 3 9}[2.06-2.79]$ \\
Obese II $(>=30)$ & $\mathbf{1 . 8 5}[1.43-2.40]$ & $\mathbf{1 . 6 8}[1.33-2.12]$ & $\mathbf{2 . 4 7}[2.11-2.88]$ & $\mathbf{3 . 0 3}[2.44-3.71]$ \\
\hline
\end{tabular}

${ }^{a}$ Bold figures were statistically significant at $p<0.05$

${ }^{b}$ Covariates available in 2013

${ }^{\mathrm{C}}$ Average values of covariate confounders in 2009 and 2013

greater than for those with 'reverting' LBP. The lowest ADL limitation rate was among those who had never reported LBP and we classified that as the reference rate. Such a longitudinal study of low back pain is important because it enables comparisons across time and between countries and permits causal analyses. Evidence on back pain and its effects is limited in low and middle-income countries. Similar to findings in Western economically advanced countries, our results reveal that low back pain was common and associated with clinically important limitations in activities of daily living among middleaged and older Thai adults.

Our findings highlight the high prevalence of low back pain across all age groups in our Thai population, as reported for studies in other groups $[1,5]$. Low household income was associated with both functional limitations and low back pain in our study, and this has also been reported elsewhere $[2,18]$. The relationships between physical activity and presence of low back pain have also been reported previously [19-21]. We also noted an association between reduced physical activity and increased likelihood of low back pain. As well, we found an association between reduced physical activity and increasing functional limitations for ADL among Thai adults. Being obese has been reported to be associated with functional limitations [22, 23], and this was also found in our study.

We note some grounds for caution in interpreting our findings. First, our study data are drawn from a selfadministered questionnaire and are subject to imperfect recall and varying individual thresholds for reporting LBP [24]. Second, while we followed the recommended international guideline for definition of low back pain for use in epidemiologic studies [13], also used by the Global Burden of Disease 2010 study [1, 5], there were slight differences in the pain diagram, with a greater area indicated in 2013. This may have resulted in higher prevalence estimates in 2013 compared with 2009. Also, our cohort was not a random population sample; even though our prevalence results may not be generalisable, the relative effects (odds ratios) should be valid. Our cohort members were open university students, all of whom had completed high school education or had equivalent experience making them better educated than average for the Thai population. On the other hand, cohort members were average working Thais in terms of their modest incomes and their geographic locations embedded in communities throughout Thailand. Lastly, we also examined the potential impact of non-response in 2013 of drop-outs $(n=17,784)$; in 2009 these were only slightly higher than the response group ( $2 \%$ for low back pain in 2009 and $0.5 \%$ for serious low back pain).

Another consideration is that the questions about functional limitations in activities of daily living were not linked with the question on LBP status. The ADL questions also had no direct link to LBP questions, hence our interest in hypothetical associations was not revealed. However, we cannot conclude for every individual reporting both LBP and limited ADL that there was a link. But for the population it is reasonable to see the results as showing an adverse effect of LBP on ADL given the statistical evidence that the relationship is unlikely to be due to chance and further given the clinically reasonable connection between LBP and ADL. In fact, it should be noted that our study is longitudinal and measures exposure variables at the beginning of the observation period. This design feature is an advantage with all prospective cohort studies and improves the analyses of potentially causal relationships.

Suitable lifestyle and behavioural interventions to prevent and mitigate LBP remain elusive but the high frequency of the conditions and their associated impacts warrant population health attention. Relevant LBP risk factors such as physical inactivity and obesity are complex and follow up of a prospective cohort over 10-20 years could provide insight into causal processes and mechanisms for LBP effects on population. This is particularly important for boosting knowledge in Asia for which information is limited.

LBP causes an enormous global burden, and this is generally increasing in developing countries such as Thailand. Initiatives aimed at the prevention and management of LBP, as with all musculoskeletal conditions, must be well-integrated with other non-communicable disease programs, rather than being stand alone [25]. This will avoid duplication of efforts and will help to promote a more-streamlined, cost-effective approach to overall health system strengthening. 


\section{Additional file}

Additional file 1: 2009 and 2013 Thai Cohort Study low back pain questions. (DOCX $50 \mathrm{~kb}$ )

\section{Abbreviations}

ADL: Activities of Daily Living; AOR: Adjusted Odds Ratio; Cl: Confidence Interval; LBP: Low Back Pain

\section{Acknowledgements}

We would like to thank our cohort members for their participation in the study and editorial support from Peter Sbirakos on the earlier version of the manuscript.

\section{Funding}

The Thai Cohort Study was supported by the International Collaborative Research Grants Scheme with joint grants from the Wellcome Trust UK (GR071587MA) and the Australian National Health and Medical Research Council (268055), and as a global health grant from the NHMRC (585426). RB is supported by an NHMRC Senior Principal Research Fellowship.

\section{Availability of data and materials}

All of the data supporting findings are contained within the manuscript. Disaggregated data cannot be made publicly available because of ethical restrictions. Please contact Principal Investigators Professor Adrian C. Sleigh (adrian.sleigh@anu.edu.au) or Associate Professor Sam-ang Seubsman (sam-ang.seubsman@anu.edu.au).

\section{Authors' contributions}

W conceptualised the study, with input and guidance from $D H, R B, C B$, and $A S$. $W$ analysed data and wrote up the findings. $\mathrm{DH}, \mathrm{RB}, \mathrm{CB}$, and $\mathrm{AS}$ provided critical comments through various iterations of the draft manuscripts. SS and AS led the Thai Cohort Study. All authors read and approved the final manuscript.

\section{Competing interests}

The authors declare that they have no competing interests.

\section{Consent to publication}

Not applicable.

\section{Ethics approval and consent to participate}

Informed written consent was obtained from all respondents. Ethics approval was obtained from Sukhothai Thammathirat Open University Research and Development Institute (protocol 0522/10) and the Australian National University Human Research Ethics Committee (protocols 2004/344 and 2009/570). Data were anonymised before analysis.

\section{Author details}

${ }^{1}$ Centre for Research on Ageing, Health and Wellbeing and Department of Global Health, Research School of Population Health, The Australian National University, Canberra, Australia. ${ }^{2}$ Research, Evidence and Information Programme, Public Health Division, Secretariat of the Pacific Community, Noumea, New Caledonia. ${ }^{3}$ Department of Epidemiology \& Preventive Medicine, School of Public Health and Preventive Medicine, Monash University, Melbourne, Australia. ${ }^{4}$ Monash Department of Clinical Epidemiology, Cabrini Institute, Melbourne, Australia. ${ }^{5}$ QIMR Berghofer Medical Research Institute, Brisbane, Australia. ${ }^{6}$ School of Human Ecology, Sukhothai Thammathirat Open University, Nonthaburi, Thailand. ${ }^{7}$ National Centre for Epidemiology and Population Health, Research School of Population Health, The Australian National University, Canberra, Australia.

\section{Received: 26 April 2016 Accepted: 22 December 2016}

Published online: 19 January 2017

\section{References}

1. Hoy D, Brooks P, Blyth F, Buchbinder R. The Epidemiology of low back pain. Best Pract Res Clin Rheumatol. 2010;24(6):769-81.

2. Stewart Williams J, Ng N, Peltzer K, Yawson A, Biritwum R, Maximova T, Wu F, Arokiasamy P, Kowal P, Chatterij S. Risk Factors and Disability Associated with Low Back Pain in Older Adults in Low- and Middle-Income Countries.
Results from the WHO Study on Global AGEing and Adult Health (SAGE). PLoS One. 2015:10(6):e0127880.

3. Dunn KM, Hestbaek L, Cassidy JD. Low back pain across the life course. Best Pract Res Clin Rheumatol. 2013;27(5):591-600.

4. Froud R, Patterson S, Eldridge S, Seale C, Pincus T, Rajendran D, Fossum C, Underwood M. A systematic review and meta-synthesis of the impact of low back pain on people's lives. BMC Musculoskelet Disord. 2014;15:50.

5. Hoy D, March L, Brooks P, Blyth F, Woolf A, Bain C, Williams G, Smith E, Vos T, Barendregt J, et al. The global burden of low back pain: estimates from the Global Burden of Disease 2010 study. Ann Rheum Dis. 2014;73(6):968-74.

6. Global Burden of Disease Study C. Global, regional, and national incidence, prevalence, and years lived with disability for 301 acute and chronic diseases and injuries in 188 countries, 1990-2013: a systematic analysis for the Global Burden of Disease Study 2013. Lancet. 2015;386(9995):743-800.

7. Volinn E. The epidemiology of low back pain in the rest of the world. A review of surveys in low- and middle-income countries. Spine (Phila Pa 1976). 1997;22(15):1747-54.

8. Hoy D, Toole MJ, Morgan D, Morgan C. Low back pain in rural Tibet. Lancet. 2003;361(9353):225-6.

9. Jin K, Sorock GS, Courtney TK. Prevalence of low back pain in three occupational groups in Shanghai, People's Republic of China. J Safety Res. 2004;35(1):23-8.

10. Janwantanakul P, Sitthipornvorakul E, Paksaichol A. Risk factors for the onset of nonspecific low back pain in office workers: a systematic review of prospective cohort studies. J Manipulative Physiol Ther. 2012;35(7):568-77.

11. Sleigh A, Seubsman S. Studying the Thai Health-Risk Transition. In: Butler C, Dixon J, Capon A, editors. Health of people, places and planet : reflections based on Tony McMichael's four decades of contribution to epidemiological understanding. Canberra: ANU Press; 2015. p. 155-76.

12. Sleigh AC, Seubsman SA, Bain C. Cohort profile: The Thai Cohort of 87,134 Open University students. Int J Epidemiol. 2008;37(2):266-72.

13. Dionne CE, Dunn KM, Croft PR, Nachemson AL, Buchbinder R, Walker BF, Wyatt M, Cassidy JD, Rossignol M, Leboeuf-Yde C, et al. A consensus approach toward the standardization of back pain definitions for use in prevalence studies. Spine (Phila Pa 1976). 2008;33(1):95-103.

14. Katz S. Assessing self-maintenance: activities of daily living, mobility, and instrumental activities of daily living. J Am Geriatr Soc. 1983;31(12):721-7.

15. Lim LL, Seubsman SA, Sleigh A. Validity of self-reported weight, height, and body mass index among university students in Thailand: Implications for population studies of obesity in developing countries. Popul Health Metr. 2009;7:15

16. Yiengprugsawan V, Banwell C, Zhao J, Seubsman SA, Sleigh AC. Relationship between body mass index reference and all-cause mortality: evidence from a large cohort of Thai adults. J Obes. 2014;2014:708606.

17. Yiengprugsawan V, Horta BL, Motta JV, Gigante D, Seubsman SA, Sleigh A. Body size dynamics in young adults: 8-year follow up of cohorts in Brazil and Thailand. Nutr Diabetes. 2016;6(7):e219.

18. Carr JL, Moffett JA. The impact of social deprivation on chronic back pain outcomes. Chronic IIIn. 2005:1(2):121-9.

19. Ryan CG, Grant PM, Dall PM, Gray H, Newton M, Granat MH. Individuals with chronic low back pain have a lower level, and an altered pattern, of physical activity compared with matched controls: an observational study. Aust $J$ Physiother. 2009;55(1):53-8.

20. Henchoz Y, Kai-Lik So A. Exercise and nonspecific low back pain: a literature review. Joint Bone Spine. 2008;75(5):533-9.

21. Heneweer $\mathrm{H}$, Staes F, Aufdemkampe G, van Rijn M, Vanhees L. Physical activity and low back pain: a systematic review of recent literature. Eur Spine J. 2011;20(6):826-45.

22. Hu HY, Chen L, Wu CY, Chou YJ, Chen RC, Huang N. Associations among low back pain, income, and body mass index in Taiwan. Spine J. 2013; 13(11):1521-6.

23. Shiri R, Karppinen J, Leino-Arjas $P$, Solovieva S, Viikari-Juntura E. The association between obesity and low back pain: a meta-analysis. Am J Epidemiol. 2010; 171(2):135-54

24. Johansson SR. Measuring the cultural inflation of morbidity during the decline in mortality. Health Transit Rev. 1992;2(1):78-89.

25. Hoy D, Geere JA, Davatchi F, Meggitt B, Barrero LH. A time for action: Opportunities for preventing the growing burden and disability from musculoskeletal conditions in low- and middle-income countries. Best Pract Res Clin Rheumatol. 2014;28(3):377-93. 